\title{
A Qualitative Study of User Perspectives on Outcomes of Orthotic Interventions
}

\author{
Natalie Hall \\ east lancashire hospitals NHS trust \\ Daniel Parker \\ University of Salford \\ Anita Ellen Williams ( $\square$ a.e.williams1@salford.ac.uk) \\ Univeristy of Salford https://orcid.org/0000-0003-1224-4347
}

\section{Research}

Keywords: Orthotic services, Outcome measures, user perspectives, qualitative

Posted Date: April 28th, 2020

DOI: https://doi.org/10.21203/rs.3.rs-24774/v1

License: () (1) This work is licensed under a Creative Commons Attribution 4.0 International License. Read Full License 


\section{Abstract}

Background: Orthotic services offer various health benefits and it is estimated that for every $£ 1$ spent on orthotic care the savings to the NHS are up to $£ 4$. Several reports into orthotic services in the UK have reported a lack of data relating to outcomes of orthotic care. This lack of data means it is difficult to demonstrate the overall efficacy of orthotic services. There is also lack of clarity about the influences on positive outcomes and we do not know what outcomes are relevant to users. This qualitative study aimed to explore the influences on outcomes of orthotic interventions and opinions on outcome measurement from the user's perspective.

Method: An advisory group involving experts in the field along with a review of the literature was conducted. From this, semistructured questions were developed, ethical approval obtained, and a focus group was undertaken with five users. Data was transcribed and analysed using thematic analysis.

Results: The participants expressed a need for orthotic provision which enables them to function physically and psychologically in the context of all life's activities. Current practice neglects the impact of altered body image and there is dissatisfaction related to waiting times, impacting on their desired outcomes. However, they expressed positive thoughts about the patient professional relationship and being involved in decision making. They identified fundamental issues around usability of three current outcome measure tools with no one outcome measurement tool being suitable for their complex conditions and interventions.

Conclusions: Communication of the clinicians understanding about the physical, psychological and socio-economic impact of living with a chronic condition, being involved in decision making, continuity of care and timeliness of provision were identified as key factors influencing positive health outcomes. Due to the complexity of conditions presenting to orthotic services it would seem that there needs to be a range of outcome measures specific to the user's condition and the orthoses provided for it. Mutually agreed and individualised goal setting may be a solution that ensure the user can self-monitor positive health gains and services can provide evidence for effective outcomes.

\section{Background}

The National Health Service (NHS) in the UK is facing times of significant change, with unique health challenges in that by the year 2050, nineteen million people in the UK will be aged over sixty-five and eight million will be aged over eighty, producing a strain on NHS resources [1]. Further, over half of the UK adult population could be obese by 2050 [2] with associated health complications, such as cardiovascular disease, diabetes, cancer and various musculoskeletal disorders [3].

In order to meet these increasing demands, various government reports have provided recommendations on how the NHS can work more efficiently, whilst still aiming to maintain high quality care for service users. In 2008, the Darzi report [4] expressed the need for providers within the NHS to demonstrate the efficacy of their treatments and services and also offering patients more choice, emphasising the importance of the review of the patient experience.

Orthotic services have the potential to improve quality of life by assisting independence and keeping people mobile for longer [5]. They are also considered to improve quality of life by reducing pain and reducing the need for more invasive and expensive interventions like surgery and social care [6]. Hence, effective orthotic services are perceived to have significant health, quality of life and economic benefits. However, in 2009 Hutton and Hurry [7] reported the lack of data on clinical outcomes does not allow for formal economic analysis.

In order to justify and ensure the appropriate funding is provided for orthotic services, and also demonstrate efficacy for the estimated two million users, there is a need to routinely audit and collect relevant outcomes data [8]. This data should be focused on outcomes of care to ensure it is line with the current government's agenda and vision $[6,9]$.

There is little evidence regarding the outcomes of orthotic care in the UK for the users themselves despite service user experience being highlighted by the NHS mandate to ensure its validity in 'making a difference to people's lives'. Hence there is a need for outcome measurement to be relevant to the users

This qualitative study therefore aimed to explore the influences on outcomes from orthotic interventions and opinions on outcome measurement tools from the user's perspective. 


\section{Methods}

Following ethical approval from the University of Salford and IRAS (UoS REF: HSR1617-113; IRAS REF: 17/NW/0379) an overarching qualitative approach was used for data collection and analysis.

The researcher took an interpretivist approach to the research project with a view that participants 'actively interpret or make sense of their own environment and of themselves' (p. 27) [10]. Interpretivism holds the view that truth and knowledge are established at an individual level and that researchers cannot separate themselves from their own beliefs, in fact these will inevitably influence the research process from beginning to end [11]. For this research, the researcher was an orthotist by profession and the insight and previous clinical experiences were considered to be beneficial in relation to the development of the research design and data collection/analysis.

An advisory group of two orthopaedic consultants, a senior physiotherapist, senior podiatrist and a senior orthotist informed the data collection process and the questions for data collection. The method of data collection was a focus group in order to provide service users with an opportunity for discussion and hence reveal and trigger different thoughts and ideas around aspects important to orthotic care [12].

Purposive sampling was undertaken to select those considered representative of the field of research and to gain understanding of the specific group being studied, not to establish claims of generalisability [13]. The participant inclusion and exclusion criteria were, currently a user of orthoses; able to and agreeing to attend a focus group and aged 18 years or over.

Prior to the focus group, the participant information letter was posted out to service users who met the inclusion criteria and five were able to attend. The focus group took place at an NHS trust site. Consent forms were completed, and assurances made about confidentiality and anonymity. After a brief introduction from the researcher the focus groups began with an opening question and were structured according to Krueger (1998) [14]. The focus group was digitally recorded and a notetaker recorded field notes. The questions were semi structured and were to act as a guide, aimed to create and direct the discussion but not to set it.

The researcher transcribed the audio recordings verbatim. Each participant was allocated a numerical participant number to achieve anonymity. All data was saved on a password-protected server. Analysis of the data was undertaken using thematic analysis [15] in order to identify, analyse and create themes and patterns within data. The researcher aimed to focus on what was said within the focus group and how this linked to previous literature in the field but also if it could reveal new themes [16]. The transcripts and the themes developed from the data were then reviewed within the advisory group, allowing for refining of the themes and subthemes and triangulation of the data [15].

\section{Findings}

The five participants are described in Table 1 
Table 1

Service User Focus Group Demographics

\begin{tabular}{|c|c|c|c|c|c|}
\hline Participant & 1 & 2 & 3 & 4 & 5 \\
\hline Gender & Male & Male & Female & Female & Male \\
\hline Age & 56 & 53 & 56 & 71 & 61 \\
\hline $\begin{array}{l}\text { Orthoses } \\
\text { used }\end{array}$ & $\begin{array}{l}\text { Modular Diabetic } \\
\text { footwear and } \\
\text { total contact } \\
\text { insoles }\end{array}$ & $\begin{array}{l}\text { Modular } \\
\text { Diabetic } \\
\text { footwear and } \\
\text { total contact } \\
\text { insoles }\end{array}$ & $\begin{array}{l}\text { Made to } \\
\text { measure } \\
\text { Diabetic } \\
\text { footwear and } \\
\text { total contact } \\
\text { insoles }\end{array}$ & $\begin{array}{l}\text { Made to measure footwear/Cradles } \\
\text { and raise; Knee ankle foot orthosis; } \\
\text { Below knee ankle foot orthosis; } \\
\text { Lumbosacral orthosis }\end{array}$ & $\begin{array}{l}\text { Made to } \\
\text { measure } \\
\text { footwear }\end{array}$ \\
\hline $\begin{array}{l}\text { Clinical } \\
\text { condition/ } \\
\text { problem }\end{array}$ & Charcot foot & $\begin{array}{l}\text { Pain in feet; } \\
\text { Pins and } \\
\text { Needles }\end{array}$ & $\begin{array}{l}\text { Different size } \\
\text { feet; Pain in feet; } \\
\text { Pins and } \\
\text { Needles }\end{array}$ & To enable to walk; To support back & $\begin{array}{l}\text { Loss of } \\
\text { Limb }\end{array}$ \\
\hline $\begin{array}{l}\text { Medical } \\
\text { Conditions }\end{array}$ & $\begin{array}{l}\text { Type } 1 \text { diabetes; } \\
\text { Depression; High } \\
\text { blood pressure }\end{array}$ & $\begin{array}{l}\text { Diabetes; } \\
\text { Back; } \\
\text { Problems } \\
\text { Arthritis; } \\
\text { Angina }\end{array}$ & $\begin{array}{l}\text { Diabetes; } \\
\text { Arthritis; Angina }\end{array}$ & Polio & Diabetic \\
\hline Years used & 10 & 6 & 7 & Since Birth & 5 \\
\hline $\begin{array}{l}\text { Hours per } \\
\text { day used }\end{array}$ & 12 hours & 12 hours & 12 hours & 15 hours & 12 hours \\
\hline $\begin{array}{l}\text { Employment } \\
\text { status }\end{array}$ & $\begin{array}{l}\text { Unemployed/long } \\
\text { term sick }\end{array}$ & $\begin{array}{l}\text { Unemployed } \\
\text { due to } \\
\text { disability }\end{array}$ & Housewife & Retired & Unemployed \\
\hline $\begin{array}{l}\text { Other } \\
\text { intervention }\end{array}$ & $\begin{array}{l}\text { Mental Health } \\
\text { team }\end{array}$ & $\begin{array}{l}\text { Podiatry; Eye } \\
\text { specialist }\end{array}$ & $\begin{array}{l}\text { Podiatry; Eye } \\
\text { Specialist }\end{array}$ & Podiatry & Podiatry \\
\hline
\end{tabular}

\section{Themes and Subthemes}

Overall, the researcher identified four themes from analysis of the data. Within each theme, the researcher identified subthemes that contributed to the main themes.

Table 2

Themes and Subthemes of Service User Focus Group

\begin{tabular}{|c|c|c|}
\hline THEMES & TITLE OF THEME & SUBTHEMES \\
\hline \multirow[t]{2}{*}{ Theme 1} & Influences before Orthotic Provision & The Impact of condition/ chronic disease \\
\hline & & Preconceptions of Orthotics \\
\hline \multirow[t]{2}{*}{ Theme 2} & The Positives of Orthotic Provision & Personal relationship \\
\hline & & Appreciation \\
\hline \multirow[t]{3}{*}{ Theme 3} & The Limitations of Orthotic Provision & Orthotist/Technician Role \\
\hline & & Compromise on Clothing Choices \\
\hline & & Negative Impact of Waiting Times \\
\hline \multirow[t]{2}{*}{ Theme 4} & Opinion on Outcome Tools & The need for complex tools for complex conditions \\
\hline & & Opinion on Format \\
\hline
\end{tabular}

Theme 1: Influences before provision of orthoses 


\section{Subtheme: The Impact of Condition/ Chronic Illness}

Participants were initially asked to describe their journey towards orthotic treatment. This was an attempt explore their possible thoughts and feelings at the time of being referred. One participant described how orthotic provision started early in childhood:

"... I got polio when I was a six-month-old, so obviously I learnt to walk with two long callipers, surgical boots and a full back support and I've carried on with that all my life." Participant 4.

She described the initial years and subsequent life as being completely dependent on her orthosis for mobility:

"So, I went into hospital at 6 months of age and came home at 2 and 1/2 as I say with two long callipers, full back support and surgical shoes and that's how I learnt to walk." Participant 4

For others, orthotic management was required later in life, following what they described as a sudden onset of illness:

"I went along with it because after the shock of having my Charcot foot and it is collapsing and having no idea how that had occurred or what was going on I was prepared to try anything." Participant 1

"I got athletes foot, that was the start of my troubles, as it was getting better I stood on a nail, walking about with a nail in my foot for five hours, I didn't know nothing about it... and the Doctors referred me up, and then I ended up losing this leg. I've still got this leg, but three toes on that one." Participant 5

It was clear that they had varied journeys towards provision of orthoses with two participants revealing about a negative event resulting in life changing disabilities. The potential impact of this on a service user's thoughts and feeling at the time of being referred to orthotic services could be an important consideration, especially in relation to its potential impact on outcomes of care.

Participants described the effects that their illnesses had had in a number of areas of their lives. Their illnesses often resulted in deterioration to their physical function and impacted various parts of the musculoskeletal system:

"The muscle wastage now on the left leg and the foot collapsing, even my hips are out of balance so your backs even worse so you're on even more pain killers." Participant 1

One participant who had suffered from the debilitating effects of Charcot arthropathy described the direct effect of this on his mental wellbeing:

"I think when my foot first collapsed it did impact on my depression, it's strongly linked."Participant 1

It was clear their pathologies had a significant impact on the participants everyday functioning. To add to this participant's also talked of the socioeconomic implications,

"... when he told me I would probably never go back to work then I was upset...they won't take me back on, I'm an insurance liability so I can't go back to work." Participant 5

What was clear was that illness impacted on participant's everyday lives and functioning. They referred to the impact on their mental health, the resultant loss of hobbies and one participant contributed it to the loss of their career. This highlights the need for outcome measures, utilised in the evaluation of an orthosis, to be able to not just measure the constructs of functioning but also include the potential impact on psychological and socioeconomic constructs that may be variable over time.

\section{Subtheme: Preconceptions of Orthotics}

One participant described their initial negative preconceptions around orthotics, in particular relating to the cosmesis of the device:

"I was a bit apprehensive regarding footwear as my sister was almost ten years older than me and had diabetes at the same time... and her footwear at that time as I was growing up, to be quite honest, I looked at the shoes she used to wear and they was like the old style divers boots, deep sea divers, they looked hideous"Participant 1. 
Concerns over cosmesis resulted in the participant feeling apprehensive about starting orthotic treatment. Despite these initial apprehensions the participant went on to describe how their initial concerns were eventually disproved:

"I have found over time I'm so chuffed with the footwear that we do get, it's gone past that awful look" Participant 1

For another participant it appeared that an initial lack of expectations pertaining to their orthotic care had actually resulted in positive outcomes:

"When I was first referred no I didn't expect, you know, shoes are shoes I wouldn't expect that, but since wearing them, I found it did help"Participant 2

Participants can often have preconceptions about healthcare services and devices, which could be influenced by family members or for other reasons. With this group of participants, it appeared that positive outcomes of care were inferred when these initial expectations were met or exceeded.

\section{Theme 2: The Positives of Orthotic Provision Sub theme - Personal relationship}

Throughout the focus group participants would refer to their relationship with their treating orthotist, often describing personal touches to their care in a positive light, as Participant 1 describes,

$X$ did look after us with a cup of tea, I have even had a brew while I have been sat outside, that's the way it should be...I am ...very happy with the staff and everything that's involved in orthotics, it's like more of a family.

Participants would often refer to their orthotist on a first name basis and indicate positive thoughts around feeling of being listened to and being involved in the treatment and decision-making process,

"In the days of X, I mean X looked after me for twenty years and I said to him is there any chance, but I once asked him if I could have a pattern on the toes (of the shoes), and they put a whole pattern on the toes." Participant 4

"We have $X$ in $X$ and he's fantastic, he makes you feel very comfortable and listens to you, any problems you have." Participant 2

"I think it's nice that we can come and talk...give us answers back that we want to hear, not fob us off with some fob stories like others..."Participant 5

An important part of the care for this group of service users appeared to be around perceiving that their thoughts and opinions had been listened to by the orthotist. They expressed appreciation and positive thoughts when discussing feeling part of the decisionmaking process for their orthotic care.

\section{Subtheme: Appreciation}

The principle of 'free at the point of use' healthcare in the UK meant that most participants incurred little to no financial cost in relation to their orthotic provision and they appeared to often refer to this, especially when expressing dissatisfaction with care, this would often be followed up by mention of cost:

"They're very expensive boots to produce so I'm just grateful really more than anything" Participant 1

"That's one thing I am grateful for, we don't have to pay for all this" Participant 4

Participants highlighted a sense of appreciation and gratefulness around the fact that there was no cost incurred in the provision, yet this did not necessarily correlate to satisfaction with services as the themes to follow indicate.

Theme 3: The Limitations of Orthotic Provision

Subtheme: Orthotist/Technician Role 
A female participant, utilising several complex orthoses, reflected on the separation of the traditional orthotist role into a manufacturing technician and prescribing orthotist. She felt this separation of expertise negatively impacted the care she now received,

"I really do think the problem is that they don't see your feet, the manufacturers don't see your feet....is a big problem I mean I have the moulds taken, I have the measurements taken they draw round my feet they do every measure they possibly can. They put the soles and heels on the shoes, and you can't get them on. I can't understand that"Participant 4. She reflects on her previous experience as a child,

"I used to go to X... and there they would try the back support on and they would say do you mind if we bring X in from the factory floor because he will be doing it and he would come in ....and they would go and do a little bit and come back and let you try it on again, you know to make sure it was alright" Participant 4

This participant, who could be considered to have complex needs, felt the separation of the prescription and manufacture process had a negative impact on her care. She described how the ability to make bespoke adjustments their and then in the past meant problems were resolved quicker and her satisfaction was increased.

\section{Subtheme: Compromise on Clothing Choices}

One participant talked repeatedly about how they had had to adjust choices in their clothing in order to accommodate or disguise their orthotic devices,

"Clothes, clothes are a big problem...If you were wearing a skirt it would look a right mess. I mean I don't wear skirts anymore, I have decided I am more graceful wearing a pair of trousers..." Participant 4

The impact this could have in the overall utilisation of an orthotic device could be an important area of consideration.

Participants, especially the female participants, described dissatisfaction and feeling uncomfortable in their orthosis during social occasions or special events:

"... you are wearing the same thing for doing the gardening as you would go to a wedding, in the same pair of shoes"Participant 4,

“...so anything, weddings... have to wear them" Participant 3

The male participants highlighted concerns about their prescribed footwear whilst on holiday, or in warmer weather:

"Think my only concern... was that in my head, was dealing with the fact that footwear on holidays, you now I have set in my mind that the boots I have got, you know, the two pairs of boots, that's all I will wear... with summer clothes... I would probably look like something out of Monty Pythons flying circus" Participant 1

"If you're on holiday or its summertime here, up to now I don't think they make any sandals, well I haven't seen any anyway in the book so, but, you've got these boots on, you know" Participant 2

Participants clearly expressed that they felt their current orthotic provision was not adequate for all aspects of their lives, especially in social settings and leads to overall dissatisfaction even if the footwear is appropriate for everyday use. This needs to be considered as clearly influences the outcome of orthotic care.

\section{Subtheme: Negative Impact of Waiting times}

Most participants expressed frustrations associated with the lengthy waiting times to receive orthoses:

"It's the time of the shoes, if it was like a month turn around it would be ok, but I am waiting six or eight weeks." Participant 5

"...it's just like you say the time gaps, I mean at one point every time a shoe went to be repaired or altered it came back and then I had six or eight weeks to be seen." Participant 4

One participant indicated that they felt the waiting time resulted in prescribed footwear often being unsuitable or unsuccessful: 
Lengthy waits to receive an orthosis were clearly an area of dissatisfaction for some of the participants and was perceived to have a negative impact on the overall quality of the orthotic care they received and hence impacts negatively on outcomes.

\section{Theme 4: Opinion on Outcome Tools}

\section{Subtheme: The need for complex tools for complex conditions}

During the focus group the researcher distributed three validated outcome measure (OM) tools that, within the literature, are suggested as being appropriate for use in orthotic practice. The Quebec User Evaluation of Satisfaction with Assistive Technology (QUEST) was originally designed to act as an outcome measurement tool to evaluate service user satisfaction with assistive technology [17]. The Orthotics and Prosthetics Users' Survey (OPUS) focuses on documenting the patient's perspective of the impact of a device and the services that provide it have on physical functioning and quality of life [18] and the EuroQol Five Dimension (EQ-5D) is a standardised tool, which can be used to measure health outcomes related to mobility, self-care, usual activities, pain discomfort and anxiety and depression [19]. When participants were asked about their thoughts and feelings of these, they identified a number of concerns. One participant, who was using more than one orthosis, found it hard to evaluate them individually,

"The thing is when you have a few different things (orthosis) it's a bit difficult to fill a form in isn't it?" Participant 4

Participants with diabetes tend to be prescribed orthotic devices to provide protection and offloading to an insensate neuropathic foot. The tools included questions about comfort, but this was a construct that was difficult for diabetic patients with a loss of feeling to answer,

"I find that difficult, you know when you have got strongly agree/disagree when it talks about comfort, you know, because if you've not got much feeling you can't, you don't know, you can't do that bit can you" Participant 1

Participants also found it difficult to relate to the specific activity levels mentioned within the tools:

"But there's certain questions about running around the block, I couldn't walk around the block, you know what I mean" Participant 1 and "I couldn't walk that far" Participant 4

Not all components of the outcome measurement tools appeared valid for all participants highlighting the difficulties that can be faced with generic measures for orthotic practice. This posed a problem for the participants in the sense that it was difficult to accurately complete the outcome measurement tool. The unique needs of individuals and pathologies could indicate the need for more specific tools or specific components within tools.

\section{Subtheme: Opinion on Format}

\section{When discussing the format of outcome tools participants expressed a clear preference:}

"Well you can study it better from a piece of paper" Participant 5 and,

"We have internet, but I still don't think internet. Want to know a meaning of a word I think dictionary, I still think the old-fashioned way. I always get cross when I can't do things on the internet"Participant 4 and,

"I don't do technology" Participant 1 and again,

"I think these are ok (paper format). Looking at the screen, changing the page up and down (shakes head)" Participant 2

For this group of service users, the preferred method was the more traditional paper format which they perceived as easier to use.

\section{Discussion}


This qualitative study achieved insight into these participants experiences on outcomes of orthoses from a service and orthoses user perspective. It also discovered factors that clearly influence outcomes such as the physical, psychological and socioeconomic consequences of living with chronic disease and preconceived expectations of orthotic services and the orthoses.

All participants were diagnosed with what could be considered chronic diseases, such as diabetes. Those who live with chronic disease are more likely to experience increased stress in daily life. This is thought to be associated with the fact that the course of chronic disease can be unpredictable and changes to health can happen on a regular basis with threats to their personal wellbeing, independence and a loss of socioeconomic stability [20, 21, 22].

Service users expressed their personal struggles with chronic disease specifically associated with the deterioration that occurred to their physical health over time and the fears they were not going to be able to fulfil their roles. Male participants talked of the loss of hobbies and careers as a result of their diabetic related co-morbidities. They also referred to the impact of chronic disease on their mental health, one participant talked of how it made them feel down and another talked of the depression that they suffered as a result. These difficulties can often lead to those living with chronic disease to withdraw from social encounters; this includes encounters which may involve treatment and rehabilitation settings, which could have a significant impact on the outcomes of care $[20,23]$.

Most service users presenting to healthcare providers will invariably hold pre-conceptions about the care they will receive [24] and these can directly influence the eventual outcomes of care $[25,26]$. Therefore, clinicians within orthotic services need to be aware of the importance of managing service user expectations at the outset of treatment. Indeed, Lateef 2011 [27] and have highlighted its relevance in improving outcomes.

The patient/professional relationship was an important aspect of care with some participants talking about how they could have open and honest conversations with their orthotist, where they felt listened to and included in decisions. Research has highlighted the importance of the patient/professional relationship, explaining how a good relationship can even increase the likelihood of adherence with medical interventions [28] and satisfaction [29]. In relation to prescribed footwear, both Williams, Nester and Ravey (2016) [30] and Van Netten et al (2017) [31] identified that effective communication techniques could improve acceptance of footwear as a health intervention and hence outcomes with it. It was also important to users to maintain continuity in their care to allow for open and honest conversations about their requirements. This needs to be considered when thinking of how orthotic services are delivered. Issues related to a lack of continuity have been highlighted in orthotic practice, in an Arthritis Research UK report (2012) [32] when it was found that only thirty percent of service users were able to see the same practitioner on return appointments leading to patient dissatisfaction with the continuity of care.

Little is known about how patient education is communicated and how successful it is in use of orthoses and improving outcomes. The practice of providing information and expecting immediate change has been thought to create a negative culture of blame for service users as non-compliant [33]. It is now considered that for health education to be viewed as successful it needs to motivate a patient to put the advice provided into practice [34,35] Arts et al (2014) [36] highlighted that there is a lack patient information or education when footwear is provided and that it is not simply a knowledge transfer from professional to service user but is a process over time which starts with knowing the patient's expectations and personal goals.

Participants also expressed dissatisfaction around their current orthotic allowance, which they felt was insufficient. One participant described frustrations around having to utilise her orthotic footwear for both domestic and social situations. A call to action paper for rheumatoid arthritis [32] found that forty five per cent of trusts only provided patients with one pair of shoes as standard, and a second pair were only offered for specific needs. When considering how most individuals wear different shoes for different life situations this may reflect an inadequate allowance and hence negatively influence the potential for positive outcomes.

Body image is thought to refer to a person's mental representation of their body and chronic illness is considered to alter a person's body image [37]. When a visible orthosis is applied to the body it would seem inevitable that this perception of body image could be negatively affected. It has been highlighted by Williams Nester and Ravey [30] that therapeutic footwear, unlike any other intervention replaces something that is normally worn and is part of an individual's body image and that footwear has to fulfil both the clinical requirements and social needs. These notions were also revealed within the focus group. Both male and female participants talked of how others would perceive them and their orthosis. Additional factors such as the length of time to receive

Page 9/13 
their orthoses and waits between appointments contributed to dissatisfaction, but there was also gratitude related to the fact the devices did not come with a financial cost to the individual.

When prescribing orthotic devices services should give thought and consideration to the potential impact on body image that the device may have and ways these can be accommodated for service users to increase the likelihood of acceptance and satisfaction and hence outcomes. Some recent work focusing on acceptance of therapeutic footwear expressed the need to employ effective communication techniques to assist patients to be involved in choosing their footwear, rather than passively receive them [31]

These service users expressed frustrations related to what they felt where lengthy waiting times to receive their orthoses. This appeared to impact heavily on their perception of their quality of care and satisfaction with orthotic services. Waiting times in orthotic services have been highlighted previously. In 2012, the Arthritis Research UK Report [32] found that seventy five percent of orthotic users were unhappy with the length of time it took to receive their orthoses. Further, NHS England [6] found waiting times for an initial assessment to orthotic services could extend up to 58 weeks and resulted in dissatisfaction with care. In order to improve outcomes, there is a need to ensure orthotic devices are provided within a timely manner. This however is a challenge in the current climate which means an increased pressure on services combined with a shortage in orthotic services workforce [38].

Patient satisfaction is a complicated and multifaceted term though commonly used as indicator of quality care [39]. Research into the concept of satisfaction in healthcare has questioned its validity as an outcome and how it may only demonstrate adequate care rather than positive health outcomes. Satisfaction can also be heavily attributed to other factors such as the relationship between service user and professional relationship rather than care received as a whole [40]. This aligns with the what the participants in this study revealed in that they expressed their frustrations but would then talk positively of the treating orthotist. In this study, the participants expressed satisfaction with aspects of their care but not all of their care. All aspects could be considered to influence outcomes and thus need to be considered together to correctly evaluate overall satisfaction [41].

While the outcome measurements tools viewed during the focus group $[17,18,19]$ were considered to be inappropriate for the complexity of these users' conditions, ascertaining and adjusting the user's perceptions and expectations prior to the intervention and then goal setting may be the way that outcome can be measured, albeit subjectively. Goals can be identified with patients and developed during the initial stages of treatment in order to create individualised goals and identify any potential barriers they could have in achieving them [42]. However, there needs to be an understanding that these goals may not remain static with an evaluation and readjustment of goals and outcomes over the course of treatment. There is also a need to ensure that outcomes related to orthoses reflect the change brought on by the orthosis alone and different types of tools may be needed for this, this may be where the relevance of disease specific measures or clinical measures are highlighted. The use of validated tools for the disease group may be an effective way in ensuring the area to be measured is recorded accurately. Whilst there is a clear benefit to using technology for collection of outcome measurement in terms of access and visibility of data collected, it may be that certain patient groups would prefer a more traditional approach, and tools/databases which consider this will have more ability to capture as wide an audience as possible.

This study is not without some limitations as the researcher and the environment has the potential to introduce bias [43]. The researcher attempted to deal with this by providing information to the participants about confidentiality and anonymity and also by sharing data with members of the research team. Further, the participant number could be considered to be small. However, the findings are not meant to be generalizable, but more to act as a exploration into a new area [44].

Based on the results from this study it is clear that further research is needed in relation to developing appropriate outcome measurement tools and methods for people with complex problems and multiple orthotic interventions.

\section{Conclusions}

Outcomes for orthotic service users are influenced by the context of their existing chronic disease and their initial expectations of the service or devices provided. These participants expressed a need for orthotic provision which enables them to function physically and psychologically in the context of all life's activities, with current practice neglecting the impact of altered body image on acceptance and satisfaction. 
Communication of the clinicians understanding about the physical, psychological and socio-economic impact of living with a chronic condition, being involved in decision making, continuity of care and timeliness of final provision were identified as key factors to the achievement of goals and positive health outcomes. Due to the complexity of condition presenting to orthotic services it would seem that there needs to be a range of outcome measures specific to the user's condition and the orthoses provided for it. Mutually agreed and individualised goal setting may be a solution that ensure the user can self-monitor positive health gains and services can provide evidence for effective outcomes.

\section{Declarations}

\section{Ethics approval and consent to participate}

Ethical approval was granted by the University of Salford and IRAS (UoS REF: HSR1617-113; IRAS REF: 17/NW/0379).

\section{Availability of data and materials}

The datasets used and/or analysed during the current study are available from the corresponding author on reasonable request.

\section{Competing interests}

All authors declare that they have no competing interests.

\section{Funding}

Funding for the research was provided via a combination of sources including the NHS trust at which the researcher was employed and The Orthotic Education and Training Trust (OETT). The funders did not influence the methods undertaken in the research.

\section{Authors' contributions}

$\mathrm{NH}$ collected the focus group data and preliminary analysis. DP and AW were involved in the secondary analysis. All authors contributed in writing the manuscript and all authors read and approved the final manuscript.

\section{References}

1. Cracknell, R. (2010). key Issues: The Ageing Population. Available online https://www.parliament.uk/documents/commons/lib/research/key_issues/Key-Issues-The-ageing-population2007.pdf Accessed 30-3-20.

2. Fiucane, M., Stevens, G., Cowan, M., Danaei, G., Lin, J., Paciorek, C., Singh, G., Gutierrez, H., Lu, Y., Bahalim, A., Farzadfar, F., Riley, L. \& Ezzati, M. National, Regional, and Global Trends in Body-Mass Index Since 1980: Systematic analysis of health examination surveys and epidemiological studies with 960 country-years and $9 \cdot 1$ million participants. The Lancet. 2011; 377, 557-567.

3. Withrow, D. \& Alter, D. The Economic Burden of Obesity Worldwide: A systematic review of the direct costs of obesity. Obesity Reviews. 2011; 12, 131-141.

4. Darzi, A. High quality care for all. 2008. Available online https://www.gov.uk/government/uploads/system/uploads/attachment_data/file/228836/7432.: Department of Health. Accessed 1/4/20.

5. Flynn, T., Boxer, P. (2004). Orthotic Pathfinder Report: A patient focused strategy and proven implementation plan to improve and expand access to orthotic care services and transform the quality of care delivered.UK: Business Solutions Ltd. 
6. NHS ENGLAND. (2015). Improving the Quality of Orthotic Services in England. 2015. Available online https://www.england.nhs.uk/commissioning/wp-content/uploads/sites/12/2015/11/orthcs-final-rep.pdf. Accessed 30-3-20.

7. Hutton, J. \& Hurry, M.(2009). Orthotic service in the NHS: Improving service provision. York Health Economics Consortium, University of York.

8. Audit Commission. Fully Equipped: The provision of disability equipment services to older or disabled people by the NHS and social services in England and Wales. 2000. Audit Commission Publications.

9. Centre for Economics and Business Research Ltd. The Economic Impact of Improved Orthotic Services. 2011. Available online http://www.nsoc.org.uk/evidence/Orthotics_review_Cebr_report_04\%2007\%202011.pdf. Assessed 16-3-19

10. Hammersely, M. 2013. What is qualitative research?2013. London:Bloomsbury

11. Ryan, G. Introduction to positivism, interpretivism and critical theory. Nurse researcher.2013; 25,

12. Taylor, C. Interviewing. In: HOLLOWAY, I. (ed.) Qualitative research in health care. 2005. England: Open University Press.

13. Emmel, N. Sampling and choosing cases in qualitative research: a realist approach. 2013. London: SAGE.

14. Krueger, R. Developing Questions for Focus Groups. 1998. London: SAGE.

15. Braun, V. \& Clarke, V. Using Thematic Analysis in Psychology. Qualitative Research in Psychology. 2006; 3, 77-101.

16. Patton, M. Qualitative Evaluation and Research Methods, 1990. California: Sage.

17. Demers, L., Wessels, R., Weiss-Lambrou, R., Ska, B. \& De Witte, L. An international content validation of the Quebec User Evaluation of Satisfaction with assistive Technology (QUEST). Occupational Therapy International.1999; 6, 159-175.

18. Heinemann, A., Bode, R. \& Reilly, C. Development and Measurement Properties of the Orthotics and Prosthetics Users' Survey (OPUS): A comprehensive set of clinical outcome instruments. Prosthetics and Orthotics International. 2003; 27, 191-206.

19. EUROQOL Research Foundation. (2017). Available online https://euroqol.org/eq-5d-instruments/how-can-eq-5d-be-used. Accessed 01/04/20.

20. Horowitz, M. Stress-response Syndromes: a review of post traumatic and adjustment disorders. Hospital Community Psychiatr.1986; 37, 241-249.

21. Livneh, H. \& Antonak, R. Psychological adaption to chronic illness and disability: a primer for counselors in the psychological and social impact of illness and disability. In: Stebnicki, M. \& Irmo, M. (eds.) The Psychological and Social Impact of Illness and Disability.2012. 6th ed. New York: Springer.

22. Harrison, C., Falvo, D., Weiss, V. \& Holland, B. Medical and Psychosocial Aspects of Chronic Illness and Disability, 2017. Jones and Barlett Learning.

23. Wright, J. International Encyclopedia of the Social \& Behavioural Sciences. 2015. Amsterdam: Elsevier

24. Peck, M., Asch, A., Goold, D., Roter, L., Ubel, A., Mcintyre, M., Abbott, H., Hoff, A., Koropchak, M. \& Tulsky, A. Measuring Patient Expectations: Does the Instrument Affect Satisfaction or Expectations? Medical Care. 2001; 39, 100-108.

25. Husain, A. \& Lee, G. Establishing Realistic Patient Expectations Following Total Knee Arthroplasty. Journal of the American Academy of Orthopaedic Surgeons. 2015;23, 707-713.

26. Iversen, M., Daltroy, L., Fossel, A. \& Katz, J. The prognostic importance of patient pre-operative expectations of surgery for lumbar spinal stenosis. Patient Education and Counseling. 1998;34, 169-178.

27. Lateef, F. 2011. Patient expectations and the paradigm shift of care in emergency medicine. Journal of Emergencies, Trauma and Shock.2011;4, 163-167.

28. STAVROPOULOU, C. Non-adherence to medication and doctor-patient relationship: Evidence from a European survey. Patient Education and Counseling, 83, 7-13.

29. Heinemann, A., Fisher, W. \& Gershon, R. (2006). Improving Health Care Quality with Outcomes Management. Journal of Prosthetics and Orthotics, 18, 46-50.

30. Williams, A., Nester, C., Ravey, M. Rheumatoid Arthritis Patients Experience of Wearing Therapeutic Footwear-A qualitative investigation, BMC Musculoskeletal Disorders.2007; 8, (104). 1-8.

31. Van Netten, J., Francis, A., Morphet, A., Fortington, L., Postema, K. \& Williams, A. Communication techniques for improved acceptance and adherence with therapeutic footwear. 2017. Prosthetics and Orthotics International, 41, (2), 201-204.

Page $12 / 13$ 
32. Arthritis Research UK. (2012). A call to action: Providing better footwear and foot orthoses for people with rheumatoid arthritis. 2012 Available online https://pureportal.strath.ac.uk/files-

asset/21721603/A_CALL_TO_ACTION_Providing_better_footwear_and_foot_orthoses_for_people_with_rheumatoid_arthritis.pdf Accessed 30-3-20

33. Caraher, M. Nursing in health education: victim blaming. British Journal of Nursing. 1995; 4, (20),

34. Modeste, N., Tamayose, T. Dictionary of publich health promotion and education: terms and concepts. 2004. Jossey-Bass:San Francisco.

35. Green, L \& Kreuter, M. Health program planning: An education and ecological approach. 2005. McGraw -Hill, New York. $227-253$.

36. Arts, M., De Haart, M., Bus, S., Bakker, J., Hacking, H., Nollett, F. Perceived usability and use of custom made footwear in diabetic patients at high risk for foot ulceration. Journal of Rehabilitation Medicine.2014; 46(4), 357.

37. Schrilder E. Body image: bodily perceptions and their influence on health. Nursing Standard. 1989 2;4(13):30-2.

38. Health Education England. The future of the prosthetic and orthotic workforce in England. HEE.2017; 1-25.

39. Heideggar, T., Saal, D. \& Nubling, M. Patient satisfaction with anaesthesia - Part 1: Satisfaction as part of outcome - and what satisfies patients. Anaesthesia, 2013; 68, 1165-1172

40. Crowe, H., Gage, H., Hampson, S., Hart, J., Kimber, A., Storey, L. \& Thomas, H. The measurement of satisfaction with healthcare: implications for practice from a systematic review of the literature. Health Technology Assessment.2002;6(32):1-244.

41. Gill, L. \& White, L. A critical review of patient satisfaction. Leadership in Health Services. 2009; 22, 8-19.

42. Rose, A., Rosewilliam, S., \& Soundy, A. Shared decision making within goalsetting in rehabilitation settings: A systematic review. Patient Educ Couns. 2017. Jan;100(1):65-7

43. Noble, H., Smith, J. Issues of Validity and Reliability in Qualitative Research. Evidence Based Nursing, 2015; 18(2), 34-35.

44. Holloway, I. \& Wheeler, S. (2013). Qualitative Research in Nursing and Healthcare, Wiley Blackwell. 